\title{
Questions of Intermediality: An Analysis of Radio Listings and Radio Highlights in British Newspapers, 1920-1960
}

\begin{abstract}
Radio listings and radio highlights published by newspapers, have attracted limited scholarly interest. In many ways they appear as a form of information, reporting to the reader what the newspaper has been told will be broadcast that day. However, as I will argue in this article, radio listings and programme highlights provide an important insight into the intermedial relationship, which developed over time between radio and the print media. Indeed, the different forms they take are linked to the way newspapers and those that work there actively shape their coverage for their readerships. Listings are also important in how newspapers represent the geographic dimensions of radio, showing not only where the stations are broadcasting from but also where they are located on the airwaves. Again, these spatial representations change overtime depending on the needs and circumstances of the newspapers and broadcasters and developments happenings in the wider political, cultural and social context. In this work, I will present a discursive historical analysis of the listings and programme highlights found in British newspapers between I920 and I960 and how these forms came to represent radio in different ways for the readers. I will also, from this analysis, identify and develop concepts, such as the diachronic, synchronic, spatial and cultural intermediary, as important ways of understanding how the listings and programme highlights work to define and culturally position radio.
\end{abstract}

KeYwords: Radio listings, radio highlights radio schedules, intermediation, cultural intermediaries, radio flows

\section{Introduction}

Radio's history is, as Kate Lacey suggests (2009), made up of differing intertwined strands, which include radio programmes, radio stations, government policy, technical developments and the roles and lives of radio professionals, technicians and radio stars. ${ }^{\mathrm{I}}$ To this list, we must also include newspaper coverage. As much as this coverage is part of radio history, radio must also be viewed as part of the newspapers' own history. As Sian Nicholas argues, '[i]n the modern 


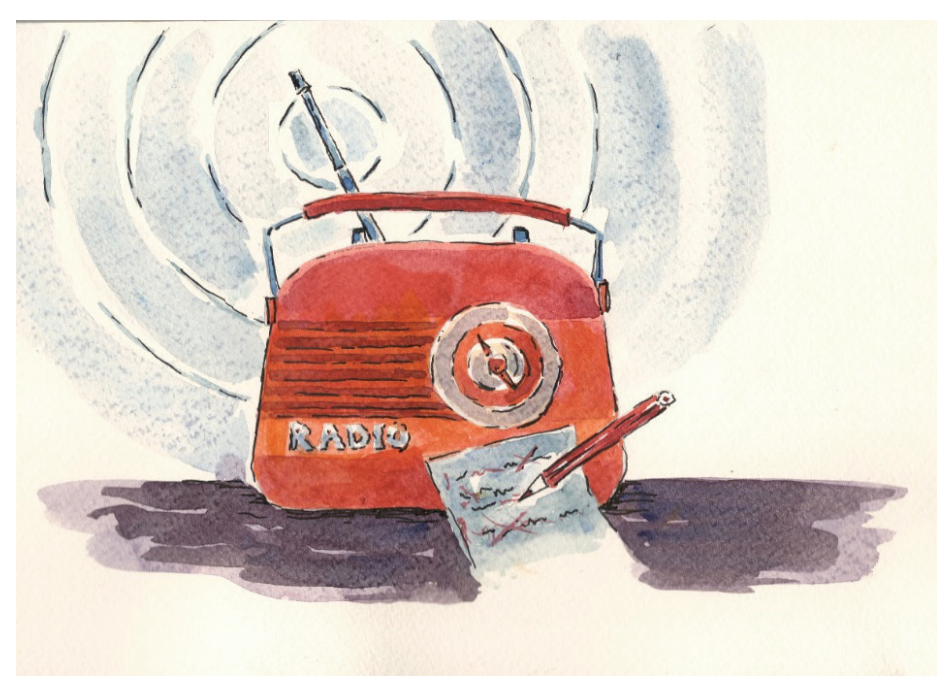

Figure 1. Radio meets radio criticism. Mandy Treptow illustration, 2019.

era there are very few events or issues (...) that can be understood with reference to just a single mass medium. ${ }^{2}$ However, it could be argued that most radio scholars have often been more interested in the output of radio and its related broadcasting organisations than the form taken by newspaper coverage, while those studying newspapers have mostly researched and written about different types of news output or journalistic practice than, specifically, radio coverage. ${ }^{3}$ In many cases, where newspapers' coverage of radio is touched on in scholarly work it is used mostly to provide 'illustrative commentary' about radio's development and its output, rather than to be critically analysed in its own right. 4

However, some research has appeared which has explored the relationship which exists between the print media and radio, such as Todd Alvery's work on radio and modernism in Britain (2006), Jeroen Dera's work on literary culture and Dutch listings journals (2017), Gwenyth L. Jackaway's work on the relationship between the press and radio in America between the I920s and I940s (I995), as well as work that has focused more on the specific role of radio critics, including work by David Hendy (20I3), Siân Nicholas (2OI2) and Paul Rixon (20I8). 5 Such work has helped to provide significant insights into the intermedial relationship that has developed between radio and print media and how this relates to wider cultural debates. However, I would argue, within these works little if any analysis has been undertaken on the changing discursive role of radio listings and radio highlights, especially in relation to the British context. For example, while Dera's work explores 'the relationship between radio and literature in the interwar period, ${ }^{6}$ it provides no analysis of the layout or format of the listings form in the British context and how these changed over time. Likewise, Jackaway's work focuses on the evident tensions between radio and the press in the US in relation to journalism and news coverage, with little analysis of the role of listings information. In a similar way, while Alvery's work provides an interesting discussion about and insight into the relationship between modernism and broadcasting between the wars in Britain, it does so without much reference to the listing schedules. However, studying listings information, the grids of information about what is being broadcast and when, can provide another way to understand how newspapers came to terms with radio and how they positioned radio for their readers as a temporal everyday 
form. As Suzanne Lommers, in relation to listing grids in Dutch radio guides, and Paul Rixon, in relation to British newspapers, have argued, such listings coverage can help us explore how the press has provided a way of representing radio to the reader.7

In this article, I will focus on exploring the form taken by radio listings and their associated highlights in the British national newspapers over the main decades of radio's dominance. This will be partly an historical analysis, focusing on what we can learn through this of the relationship which developed between radio and the press media over this time, but also a conceptual one, in terms of how we can understand the way such forms of coverage work in a more abstract manner to position radio for the public. I have chosen to focus on British coverage as each national situation has its own nuances and differences, and little has so far been written on this form in this national context. This is not to say that connections and generalisations cannot be made between different national situations, and the hope is that this article will feed into research being undertaken internationally on this form of coverage. I have chosen to look at newspapers, rather than listings magazines, as my interest is in the form of intermediality happening between two popular competing forms of media, between the newspaper and radio. While the Radio Times was, from I923, the listings magazine of the BBC, its relationship to broadcasting is particular and different to that of newspapers and, while its importance needs to be understood, its history and development are so different and complex there is not enough space to adequately explore it within this article. ${ }^{8}$

For this historical analysis, I will focus on the period from the early I920s until I960 as this is the main period of radio's dominance, both in terms of popularity but also in terms of newspaper coverage. I stop at I960, as this is the start of a period when the radio and newspaper landscapes start to change dramatically, with the continued rise in the dominance of television, a change of radio towards a more secondary form of media and with the decline in radio coverage in the newspapers, especially in the popular press. ${ }^{9}$ As I analyse the nature and form taken by the newspapers' listings and highlights, this space where two media interact, ${ }^{\text {IO }}$ I will also reflect on how the newspaper, as a cultural intermediary, plays a role in shaping this type of coverage for their particular readerships. ${ }^{\text {II }}$ Such an analysis of the listings and highlights found in the British press about radio is something that has been virtually absent from the cultural history of radio, something this article starts to address. I will begin, however, by discussing the main issues and concepts that have emerged out of the historical analysis and will reflect on how these provide new ways of understanding how such coverage works to position radio for the newspapers' readerships.

\section{Conceptualising radio listings and programme highlights}

As the historical analysis will explore, the listings are a way of representing radio's temporally organised output, its schedules, by providing a chronological list of what is broadcast and when by a radio station. By using this information, readers can plan, if they want, what they will listen to over a period in relation to this flow. ${ }^{12}$ In one way, the listings provide what could be thought 
of as, borrowing from linguistics, a diachronic view of radio, of as a process happening over time. ${ }^{13}$ However, the listings do not just provide information about one station and its chronological output, but often many, and thus the listings also provide a more synchronic view of radio; one that suggests that choice can also be viewed as operating non-chronologically across stations. ${ }^{\mathrm{I}}$ The listener, depending on the number of stations, has a choice between stations and the programmes that are being offered at any one moment. Indeed, the radio highlights reinforce this view by taking a programme out of the flow to signal its presence. Perhaps suggesting that, at certain moments in time, the notion of me-radio, a personalised form of radio, in a limited form, where the listener has a degree of control over what they want to listen to and when, has an historical precedent. 15 Therefore, the listings present two characteristics and tensions that exist in a media form like radio: one, where the flow of programmes over time is the defining feature, is often viewed as leaving power in the hands of the broadcaster to decide what choice is available and when, and another view of radio, as being defined more by a range of programme choices at any particular time, where the power to choose resides more with the listener.

The listings and highlights also represent the spatial-geography of radio in a physical form, by providing locational information about the stations, including their call sign, the frequency being used for broadcasts, the name of the station and where they are based. ${ }^{16}$ In this way, the listings provide a representation of how radio connects to physical geography, where radio is broadcasting from, but also how it relates to a more ephemeral geography, where it can be located on the airwaves via the radio set. The listings and highlights, therefore, provide not only a visual representation of how radio operates temporally, both diachronically and synchronically, but also, in another way, where it is located, physically in the world and where on the radio dial, allowing the listener a way, or a number of ways, of understanding radio, in terms of what they can tune in to, when and how it links them virtually to different places, thus allowing them a way of navigating their way around these different elements.

However, the listings and programme can take different forms depending on the newspaper in question and what information and coverage it includes, excludes and how it is represented on the page. While the term cultural intermediary could be used to refer to how a professional like a radio critic takes on a selective cultural function, ${ }^{17}$ choosing, filtering and recommending the radio they write about for their readers, ${ }^{18}$ so too newspapers can be seen as undertaking a similar role, but at a higher level, in the way they organise a range of columns and employ a number of writers to focus on radio in (a) particular way(s); therefore, the newspaper, acting as a cultural intermediary, shapes the form taken by all of its radio coverage. ${ }^{\text {I9 }}$ The way newspapers culturally shape and present a particular view of radio is determined by the readership, however imagined, they wish to reach. Therefore, for the popular press, those papers which aim at the lower socio-cultural readerships, a popular form of coverage is usually provided while, for quality papers, those aiming for readerships in the higher socio-cultural demographics, a more serious form of coverage is evident. ${ }^{20}$ Usually, at least for the main national British newspapers, with their aim to attract as large as possible readership of a distinct socio-cultural grouping, the cultural values espoused, whether in a popular or serious format, tend to be 
the dominant ones. In this way the cultural coverage of these newspapers, including that of radio, tends to be positioned in relation to and in acceptance of the dominant cultural hierarchy and, therefore, a form of maintenance of cultural values is undertaken by both popular and quality papers, though the emphasis and style will differ. However, at times, the newspaper's coverage might, alongside that of individual critics and writers, provide different and contradictory viewpoints which could help a change or shift in cultural values. ${ }^{21}$ However, as will be explored later, developments outside the direct control of the newspapers also impact on how it, and its writers, cover radio in the listings and highlights.

\section{Approach}

To explore how radio listings and associated highlights worked in British national newspapers to discursively positioned radio for their readerships between the I920s and 1960, I will divide the following analysis into three periods. While any such temporal divisions are somewhat artificial, many overlaps between them exist, they have been chosen as they reflect key moments in the developing intermedial relationship between radio and the press: the first period relates to the I920s when, as radio broadcasting was establishing itself as a mass medium, newspapers were beginning to provide early forms of listings and highlights coverage; the second period, the I930s, is a moment when radio established itself as an important mass medium and radio coverage expanded in the main national newspapers; and the last period, the I940s to I960, relates to a period when radio was still a popular media but when there was a decline in its coverage in the press, initially due to the impact of the war, but which continues into peace time, at least for the popular papers, as radio coverage was replaced by television coverage.

As I undertake this analysis, I will reflect on how these material displays of radio and its output, the listings and highlights, are shaped by the needs of papers and developments occurring in radio, within a wider understanding of the changing British cultural, social and political landscape. As part of this analysis, I will reflect on what this tells us of the underlying values of the newspapers and their role as a cultural arbiter, aligning the papers' discourses of radio and its output to the readers' tastes. To undertake this I have chosen a range of papers which echo the main division evident in the British press, on the one hand, popular papers, such as the Daily Mirror, Daily Mail and Daily Express, and, on the other hand, quality papers, those such as The Times, Daily Telegraph and Manchester Guardian (while the Manchester Guardian was a provincial paper at this time it had a national reputation and was to become a national paper in 1959). ${ }^{22}$ For each paper I have collected a sample of around ten pages of radio listings and highlight coverage for each of the first two periods noted above, and then, for the last period, around ten for the early I940s and the same number for the mid-I950..23 The samples are not meant to be representative, but rather are examples that allow an insight into the discursive developments happening in these papers within these periods. For this article, the aim is to explore the textual coverage in relation to the newspapers' imagined readership, ${ }^{24}$ rather than to undertake any in-depth reflection or research on how readers use such coverage to inform their listening habits. 
Using an initial understanding of how listings and highlights appear to operate within newspapers, I decided to use a form of discourse analysis. I have chosen such an approach as it does not start with a set hypothesis or view, but instead seeks, through the analysis, to 'describe, understand and explain particular historical events and processes', from which 'a new interpretation' can emerge. ${ }^{25}$ For my approach, to discursively explore the symbols, language and layout of the listings and highlights, to allow a discursive reading to emerge, a variety of qualitative methods were employed over four interlocking levels: firstly, I looked at where the listings and highlights appeared in the newspaper, specifically on which page it was to be found. In this way, the page where they were located on can be taken to indicate the importance the paper allocated to radio and the radio listings, whether as something that would attract readers or not and, also, depending what was placed nearby on the page, to reflect on how the paper treated this coverage compared to other news and cultural forms. At the second level, I looked at where the listings and highlights were placed on the actual page, at the top or the bottom of the page or the side, how much space they took up and how large the titles were. This can again be viewed as an indication of how important the papers viewed such coverage, and how it related to other coverage around it.

For the third level, I looked more specifically at the way the listings were formatted, which fonts were used, whether the lines were indented or wrapped around, how much information was given about the station and the programmes, how many stations were covered and what different types of emphasis were provided, such as the use of bold or underlining. This allows an understanding of how radio was being presented to the reader, whether it was with an emphasis on individual programmes or the output of the stations. It is here that I started to identity and develop the two concepts of the diachronic and synchronic, as a way of explaining the two tendencies seen at work in the listings. At the fourth level, I focused more on how the programmes were written about, which ones chosen for the highlights and what cultural references and associations were being made. As I undertook this analysis, I compared what I found within between papers, especially between the popular and quality press. Such a historical discursive approach allows an insight into how newspapers' listings and highlights worked to position radio for the readers and were part of a changing intermedial relationship between the press and radio.

\section{Listings and programme highlights: bringing radio into the newspaper (from audio to print)}

Finding a form: 1920 s

Early experiments with radio broadcasting occurred before the First World War in Britain, ${ }^{26}$ but no dedicated coverage was provided at the time by the British national papers, except in terms of news. These were 'wireless experiments' and radio was not yet developed enough to be accepted as a form of mass media. ${ }^{27}$ However, by the early I920S, as the British Broadcasting Company (BBCo) took over broadcasting in Britain, early forms of radio listings started to appear in most British newspapers. ${ }^{28}$ These provided a short chronological overview of a 
station's output, rather than taking another direction, such as just providing a selection of programmes from the station's output. In many ways, this form of coverage, listing grids of radio schedules, became one of the main forms of information provided by newspaper and listings magazines, such as The Radio Times, about radio for the rest of the century, at least until the digital era and the development of podcasts, which were positioned outside of the broadcast flow. ${ }^{29}$

The newspapers' listings, during the early to mid-I920s, mostly focused on the output of the early BBCo stations, which were initially divided into six local stations, ${ }^{30}$ providing their frequency, call sign and location, and a brief overview of what was being broadcast and when. However, it must be noted, that the Daily Mail also provided information about radio signals coming from outside of Britain with its coverage of its sponsored radio programmes being broadcasting from The Hague. ${ }^{3 \mathrm{I}}$ For example, by the early I920s the Manchester Guardian, was providing listings of the BBCo's Manchester station (2ZY (its call sign) on 385 metres (the frequency)), with a few words for each programme, e.g. '6.0-6.15 Kiddies Corners, conducted by Uncle Humpty-Dumpty and the Cloud lady.' It then, underneath, had just titles and times for the other of the BBCo's stations around the country, including $2 \mathrm{LO}$ based in London. E.g. 'II.3O a.m. - Home Exhibition.'32 The newspapers restricted their coverage to one day's listings or two at the weekend, partly as they were daily newspapers but also as the BBCo forbid any more coverage appearing. 33 In addition, because the press release system of providing information to newspapers and others about the output in advance was not well established in the early years of the BBCo, the newspapers were often unable to write in much detail, even if they wanted, about the programme and station's output. ${ }^{4}$ For these reasons, information was often brief, focusing on the title, main stars, the author, the name or title of the programme, or the name of the conductor or orchestra; often reflecting how well known the star, writer, opera, music or play were - to both writer and reader. Thus, at least at first, there was a tendency to treat radio as an extension of other media and cultural forms, about which knowledge already existed, such as with references to classical pieces of music or well-known plays e.g. '9.25. C Franck's violin Sonata in A major, with introductory historical notes. ${ }^{3} 5$

For the Daily Mirror, a popular national newspaper, radio listings are sparse with only the London station $2 \mathrm{LO}$ covered and with little information beyond the title or main contributor e.g. '5.0 - Children's stories; 7.0 news; 7.15 - Miss Nellie Norway (hand bells solo). ${ }^{36}$ This listing information is placed near some other news on radio telephony but on a page mostly made up of general news. As with most papers at this time, it is not the focus of attention or situated as a popular attraction on the page. It had to be sought out by a reader who might want this limited form of information. There is little detail provided here on many programmes or their content, with most information being about the cultural form, music or drama for example, coming via the radio broadcast e.g. operas or classical concerts.

In this early period, often without much demand by the public and with little information or pre-understanding of the programmes, few highlights appeared in most newspapers. The listings information was viewed as providing as much information as the papers would want to make available for a competitor and focused mostly on British stations. Indeed, for a short 


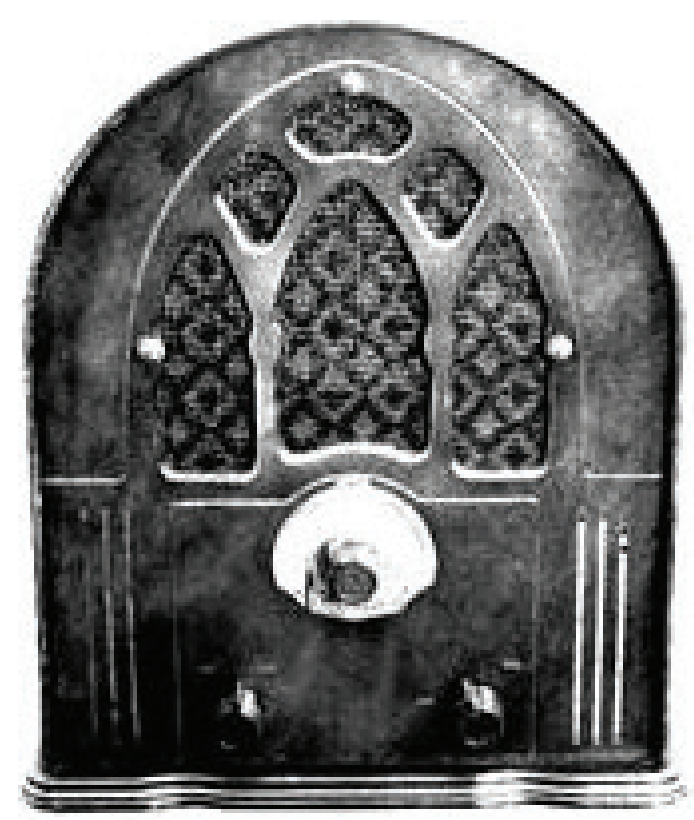

Figure 2. Early valve radio set. Source: Thomas Ford Memorial Library.

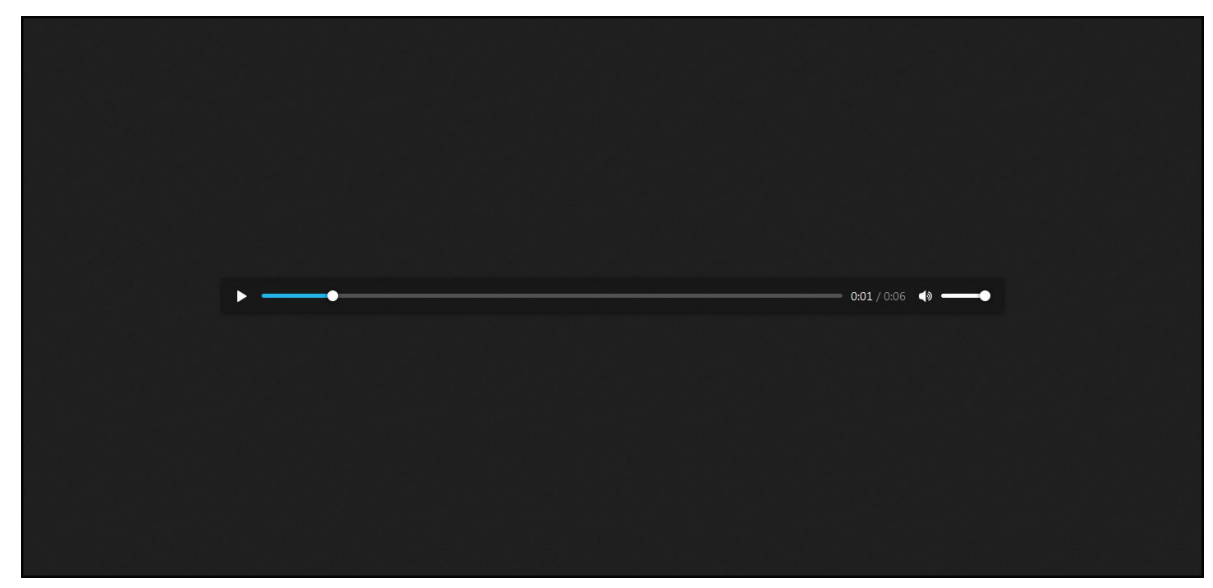

Figure 3. Call sign of $2 L O$ the BBC's first broadcasting station (audio).

period the newspapers, in I923, stopped publishing listings coverage and asked for payment from the BBCo for providing such information, seeing it akin to free advertising. 37 The BBCo did not pay up, and instead it went on to set up a listing publication, The Radio Times. ${ }^{8}$ The newspapers' listings prohibition was eventually broken by an advert sponsored by Selfridges, published in The Pall Mall Gazette, which carried the BBCo's listings information, which, as the Gazette sales suddenly increased, led to all the newspapers again providing listings information. 39 While the listings took up only a small part of a page it was increasingly seen as something the public wanted and the papers had to respond and keep including them, or else lose readers to a competitor paper. ${ }^{\circ}$ 
All papers at this time focused on the station nearest the market they served or ones that reflected the paper's standing, e.g. The Manchester Guardian, as a provincial quality paper, focused its coverage on 2ZY the Manchester station, while The Times, a national quality paper, and the Daily Mirror, a popular national paper, both had as their focus 2LO broadcasting from London, the UK's capital, which was becoming the main feeder station for a national service as relays start to develop during the I920s. This meant newspapers tended to represent the limited number of British radio stations that were available with a diachronic bias, with most information provided in terms of the chronological output of one main station, usually highlighted at the top of the listings, rather than focusing more on the choice of programmes in any one time slot. Spatial information was also provided at this time by all papers, including frequencies, call signs and geographic locations, based on cities, with almost all the stations covered being within the UK. The representation to the reader is, very much, that this is a nationally bounded media form, provided locally, though for some listeners, who were starting to explore the international reach of the radio waves, it evidently was not.

Radio's rise as a popular medium and an expansion of listing information in the newspapers: 1930 S By the middle of the I930s, radio was established as a popular mass medium. ${ }^{\mathrm{I}}$ Newspapers, echoing this development, had expanded their radio provision, especially the popular press, that saw radio coverage as playing an important role in attracting and keeping readers. While on one hand they were still worried about radio's impact on their own businesses, and often employed critics who were critical of the BBC (British Broadcasting Corporation: incorporated as a public corporation in I927), such as Collie Knox and Jonah Barrington, ${ }^{2}$ they also saw it as something worthwhile and necessary to cover. ${ }^{43}$ And, while radio started to be represented in this period as a more international medium, the Newspaper Proprietors' Association (NPA) agreed, with concerns over losing advertising revenue, for its members not to provide coverage of commercial broadcasters based in Europe, such as Radio Luxembourg and Radio Normandy, who specifically aimed at the British market and were to become were very popular with the public in the I930s. 44

The popular press, which included such papers as the Daily Express, Daily Mail and Daily Mirror, had now established entertainment pages where radio coverage appeared, alongside coverage of the stage, film and, by 1936, television. 45 For these newspapers, the listings were an important part of this coverage and would often dominate these pages. For example, the Daily Mail on its entertainment pages, on I January I935, had put over a quarter of a two page spread to the listings. ${ }^{4}$ This gave coverage of the main national output of the $\mathrm{BBC}$, the Nation Programme, for which some programme information was provided, and its regional coverage, for which less information was given. The listings also had information about a selection of European channels, though, as noted above, not Radio Luxembourg or Radio Normandy. The listings were positioned as an attraction by the Daily Mail, as illustrated by the large title of 'To-day's Programmes', there to catch the eye of the reader. For the Daily Express, by I933, at the weekend, half a page is put over for listings information. 47 As with the Mail, the Express provided 
detailed information about the main national output of the BBC, the National Programme, and then smaller, more condensed information about the BBC's regional stations' output, reflecting the paper's national standing. It also provided coverage of 'Foreign Stations' but, instead of their full output, it had a selection of programmes broadcast by various European stations in a chronological list. E.g. 'II a.m.- Concert by Silesian Philharmonic Orchestra - Breslau $\{325 \mathrm{~m} 60 \mathrm{kw}\}$. II a.m.- Orchestra concert - Brussels $\{337 \mathrm{M}$ I5 kw\}. II a.m.- Orchestra concert-Heilsberg $\{276$ $\mathrm{m} 60 \mathrm{kw}\} .{ }^{3} 8 \mathrm{~T}$ This was a mix of a listings format, programmes from various stations provided as a chronological list by time, and a 'best-of', highlighting some programmes broadcast at these times the critic felt fit with the presumed tastes of the newspaper's readers.

By the I930s, most popular papers were providing radio highlights next to the listings to help their readers find relevant and interesting programmes. For example, the Daily Express had started to use a simplified star system for its highlights, creating an easy to understand and eyecatching way of not only picking out programmes but also suggesting how good or interesting they were, which fits with the popular way they also covered the news. 49 For example, on 20 June 1938, three programmes are picked out, The Bungalow Club (1938), which got three stars, Radiolympics (1938), which got four stars and Maurice Winnick and his Orchestra (1931-50), which got two stars..$^{\circ}$ This selection of popular material compares with the Daily Mail, which recommends more serious forms of listening, '6.30, REGIONAL and WESTERN: Wireless Military Band. 7.30, NATIONALS: Music of George Posford. 8.30, NATIONALS: Lost Voyage.'51 Such highlights took programmes out of the flow, out of the chronological lists of a station's output, and presented them as standalone programmes that readers could listen-in to at a particular time. The programmes the popular papers tended to highlight, were a mix, there were still more elitist forms of culture, such as classical concerts and operas, but they also included more popular programmes, including comedies, drama and popular music, which represented the developing popular radio form.

Unlike popular papers the quality papers, those such as the Manchester Guardian, Daily Telegraph and The Times, by the mid-I930s, had not created similar styled entertainment pages, but instead had divided their radio coverage into two main parts: the reviews of radio programmes appeared on existing review or art pages, while the listings and highlights information appeared elsewhere in the paper. This was an attempt, in some ways, to separate out a more serious cultural acceptance and treatment of radio, the review, from the more mass media type of coverage, with its focus on flow, the listings and highlights..$^{2}$ The way these papers covered radio was made to fit with the way they covered other cultural forms and positioned radio in a way their readers could understand and accept. The Daily Telegraph, still using narrow ridged columns throughout the paper, provided listings on a similar scale to the Manchester Guardian and The Times, covering the BBC National Programmes, its regional output and around 27 European channels. 53 Most information was provided for the BBC's National Programme, with less for regional and European broadcasts, reflecting the paper's national standing. While the listings took up around a quarter of one broadsheet page, it was still dense and hard to read. For the Manchester Guardian, on 8 May I937, the main focus was on the BBC's 'North' regional station (449.I Metre: 668 Kcs.), reflecting the paper's provincial standing as a Manchester based 
paper, and the 'Droitwich National' (I,500 Metres: 200 Kcs.), transmitting the National Programme; underneath these were the regional channels, a small listings section covering television and then twelve European stations under the title of 'Foreign Stations'.54 The Times offered similar coverage to these two papers, its coverage was divided into two, with the UK based channels appearing under 'Home Stations', which included the national and regional channels, and the European stations, which numbered around thirteen, including those broadcasting from Berlin, Beromunster, Budapest, Cologne, Hilversum, Leipzig and Milan, which appeared under the title, 'Foreign Stations.'55

In relation to the highlights, the quality papers all provided regular selections, most of which focused on the more serious cultural output of the stations, both at home and from Europe, which aligned with the socio-cultural backgrounds of their readers. For example, the Manchester Guardian, on 8 May I937, positioned its highlights above its listing information but within the same column; the highlights were given in two forms, the first part had the selected programmes offered as a mini-listings showing the times they were to be broadcast, followed by more detailed information about the programmes. The programmes covered include Scrapbook, an historical documentary, the Rugby League Cup final, and an Opera, Merrie England..$^{6}$ For The Times, highlights were provided at the top of the radio column, above the listings. For examples, on 24 January 1935, the column recommended, "Bach Mass in B Flat", which was to be broadcast on the Northern transmitter. Another programme, described by its content, was mentioned, which offered, a 'selection of Swiss music from Radio-Paris'. ${ }^{57}$

By the mid-I930s the newspapers' listings information now provided coverage of a wide selection of stations which could be picked up by British listeners, this included all the output of the BBC, the National Programme and Regional stations, and a selection of international services. One of the reasons for this wide array of stations on offer is that it was an attempt by newspapers to react to the monopoly position of the BBC, to show readers that there were alternative broadcasters..$^{8}$ However, as noted earlier, they were selective in how they did this, and offered no coverage of those European based stations they saw as a commercial threat, such as Radio Luxembourg. In some ways, there was, by now, much more of a balance between the diachronic and synchronic, between a representation of radio as a temporal flow and radio offering extensive choice between programmes on offer at the same time. For example, most papers' listing information focused on the output of the National Programme and, therefore, foregrounded a view of radio as a chronological form from which the reader must choose; but, at the same time, all the papers, including the Daily Mail and The Times, also provided coverage of regional and European stations, and thus stressed the idea of a large amount of choice existing at any one moment, and therefore the synchronic aspect of radio. Helping reinforce this break with the chronological flow of radio, was the increased provision of daily radio highlights which picked programmes out of the schedules offered by all papers. The popular papers mostly highlighted a mix of serious and popular programmes while the quality papers tended to focus more on serious and cultural programmes, reflecting the different socio-cultural backgrounds of their readerships. On another level, by including a mix of British national and regional stations and international stations, the listing provided the readers with a geographic awareness of radio 


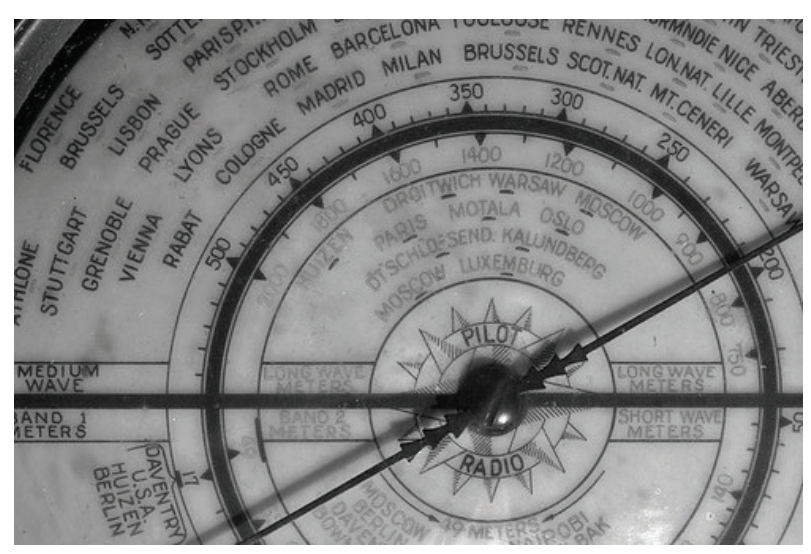

Figure 4. Example of an old radio dial, showcasing the scope of the international radio landscape. Undated. Source: Pedro Moura Pinheiro (Flickr).

operating not only locally and nationally but also internationally. The stations titles provided by the listings, usually relating to the city where the broadcaster was based, gave an exotic dispersed feel to the audio-spatial geography of this new medium, one that linked British cities to a wider imagined European, and sometimes international, space. This was reinforced by the radio dial, which could be navigated by frequency information or labels, where far away cities, and their radio stations, sat alongside British based stations.

Radio listings, the decline of coverage and the rise of television: 1940 to 1960

By the early I940s, radio coverage in all newspapers started to decline. This was not because radio had become less popular, indeed its popularity was increasing at this time, nor because the papers were necessarily less interested in providing coverage but, instead, it was because of the impact of the war.59 The war led to paper rationing, which meant all newspapers were required to reduce the number of pages they could print per issue. ${ }^{60}$ This reduction in pages squeezed all content, including all forms of radio coverage. This combined with the situation happening in Europe, where some of the stations, which newspapers previously included in their listings in the I930s, were, by the early I940S, mostly in German occupied territories and, therefore, either had stopped broadcasting or, in response to worries about propaganda, were no longer included in the radio listings. In addition, with worries about BBC regional broadcasts being used by German bombers to navigate to their targets, the BBC merged its regional services into a new national programme, the Home Service, which it launched on I September I939, just before the official declaration of war two days later. ${ }^{6 I}$ To serve the armed forces, a new Forces Radio was launched on 7 January I940, though it was to also become popular with the general public. ${ }^{62}$

This meant, the papers now only offered coverage of two stations at this time, though within less space. For example, for popular papers in the early I940s, such as the Daily Mirror, the substantial coverage on offer in the mid-I930s, including that of national, regional and European stations, had decreased to covering only these two national British stations. The Mirror's radio 
listings for II March I940 took up only half of one small column, and only covered the Home services and Forces Radio. The font was small, the lines wrapped around and only a few words of information are given, e.g. '7·45-Bing Crosby (records) 8.o-News. 8.I5-New English Trio. 8.45Harold Smart at the organ.' ${ }^{63}$ For the Daily Mail in I942, another popular paper, the radio listings appeared as part of a column, titled "Radio", covering the output of the two BBC national stations, Home (though the station name was not given), and 'For the Forces. ${ }^{6} 4$ The font was smaller than that used around it, the lines are wrapped around and only a few words are given about the programmes. These listing were hard to find, buried away on the bottom of page two and, using a small font, were hard to read. For The Times, a quality paper, the situation was similar, with the listings for Saturday and Sunday appearing on page two and now part of just one column on a broadsheet page, rather than spread across a number of columns as it was in the I930s - and covered the Home and Forces programmes. ${ }^{65}$ While it does have a title, "Broadcasting", the listings are in a smaller font than the rest of the page, the information is wrapped around and only a few words were given for each programme e.g. Home service: '7a.m. Time: News, 7.I5. Records, 7.30 Physical Exercises, 7.50. Records.'66 All the European programmes, which were covered extensively in the I930s, were now absent.

All newspapers continued to cover this important medium, but external developments had led to a change in what radio programming was available and how it could be represented. Such radio coverage was no longer seen as a necessity, or an attraction. It was still provided but had to be sought out. For the war period, there was a shift in the dominant representation, away from a balance between the diachronic and synchronic, between the chronological output of radio stations and individual programmes broadcast in any one time slot, towards the diachronic, where choice was focused on the chronological output of just two stations. Radio's spatial representation also changed, with the impact of the war it was now represented as a national medium, with no regional or international coverage. Alongside this, the exotic Europeaninternational flavour of radio that was present in the I930s, had gone. Its national position, role and importance was now foregrounded at this time of national emergency. While the markings might still exist on the dial, and the stations could still be found emanating from Europe, they were missing from the papers.

Paper rationing slowly started to lessen after the war and finally disappeared in the midI950s, allowing newspapers to begin to increase in size. ${ }^{67}$ For the popular papers, this allowed entertainment coverage slowly to start to reassert itself as a popular and important form of coverage, which included a slight expansion in the size of the listing information. This increase in listings coverage was partly required by the expansion of the number of radio channels being broadcast by the $\mathrm{BBC}$, to include not only the existing Home Service, set up in the war, but the Light Programme (I945), which came out of the General Forces Programme (a renamed Forces Programme), a new high culture Third Programme (i946) and the reestablishment of regional output as opt outs from the Home Service, moments when regional programmes would replace those provided by the national service. ${ }^{68}$ With the relaunching of television in I946, the listings coverage again came to include television as they did before the war, which, for the popular papers, began to become more dominant over time. For example, by I954, the Daily Mirror's 
listings information, while small, was contained in an eye-catching box titled "Television and Radio". In the title, television is mentioned first, signalling the shift towards television as being the more important of the two, a point that was reinforced by the television schedules appearing first at the top of the box. Radio appeared under these, divided into Home, Light and Third and then regional stations. ${ }^{6} 9$ Television had the subheading 'Television', while the radio coverage was not provided any title. The font for all the listings is smaller than the surrounding page. The information given was short and the lines were wrapped round. Of the two, television is the more dominant, which reflected the rise of television as a popular medium, but also the support many newspapers now gave to commercial television, which they hoped they could get involved with in some way..$^{\circ}$ Another reason for this shift is that their working and lower middle class readerships were increasingly more interested in the developments occurring in television with its popular appeal, compared to the more 'serious and demanding' output of BBC radio. ${ }^{7 \mathrm{I}}$ However, for the quality papers, the listings were still dominated by radio. It usually appeared at the top of the listings' column, and the coverage was of a similar size and form as television. For example, for the Daily Telegraph, radio appeared first in the listings, with the schedule for Home, then the Light programme, Third and then the regional opt outs. Only after this did television appear. The way television and radio were shown were the same and the column title, "Broadcasting Programmes,"72 mentioned neither by name.

The radio listing grids, for all papers in the I950s, both popular and quality, included all the national radio stations, such as the Home Service and the Light Programme, where some information was given for individual programmes, often in a similar or slightly smaller font than the surrounding page. Regional stations were also covered and usually appear at the bottom of the page in a smaller more tightly spaced text. For all stations, beyond the broadcast times of programmes, the title of station and the frequency they were broadcasting on, was given. This compared with television where the title, BBCI or ITV, only were given, partly as television sets tended to have switches or a knob that could easily be used to turn to the channel in question without the need to know the actual frequency. The absence of foreign stations continued after the Second World War, though Radio Luxembourg and a few other commercial stations did appear in some papers as they became more popular as an alternative to the BBC's output.73 For example, for the Daily Mail included Radio Luxembourg and the Armed Forces Network within its radio listings in 1956.74

In relation to the highlights, most of these had disappeared or had been reduced in this decade both in popular and in quality papers; in many ways, the coverage of radio never returned to what it was before the war. For the popular papers most of the surrounding coverage was now focused on television with only a few occasional references made in relation to radio. For example, on the main broadcasting page in the Daily Mail on 3I January 1956, there was only a "Teleview" review article by Peter Black, focusing on television. Radio only appeared in the listings found under his column, underneath the television listings. ${ }^{75}$ For the quality papers, there were few or no highlights for most of the I950s, though they returned in the I96os. For example, on the page where the Manchester Guardian had its listings information on I May I958, there were only the listings and no highlights. The rest of the page around the listings on this 
page contained classifieds. ${ }^{6}$ Radio and television, however, were still covered within the review sections of the quality papers, found on a different page to the listings, and in the more general news sections.

The developments happening in radio, the press and the wider society in the I950s, led to a balance of sorts between the diachronic and synchronic representation of radio. With more radio stations covered than in the war, the representation which developed suggests, on one level, that the range of national stations and regional opt outs offered choice between programmes in any one time slot, but, on the other hand, with new BBC stations focusing on particular types of output, such as the Light programme with its focus on entertainment, most readers' tastes were satisfied by one or two stations, suggesting that choice, for them, operated more within the flow of a limited number of stations than across all those available. In terms of the geographical representation, while the radio listings focused on the national output of a handful of channels, it also started to include regional channels as the BBC started broadcasting these again, initially as opt outs. 77 The international coverage of radio had now virtually gone and, when it did appear, it was only to include the output of quasi-British broadcasters, like Radio Luxembourg, which, while based in Europe, broadcast specifically, at certain times, to British listeners. However, what was most notable in this period was the start of a much more obvious divide between the decline of radio coverage provided by popular papers, and their focus on television, and the quality papers, which continued to maintain their radio coverage, such as with their listings where radio still appeared first, for their more radio orientated middle class readers.

\section{Conclusion}

The radio coverage found in national newspapers in Britain from the I920s can be viewed, in many ways, as being similar to how other media and cultural forms, such as film and theatre,

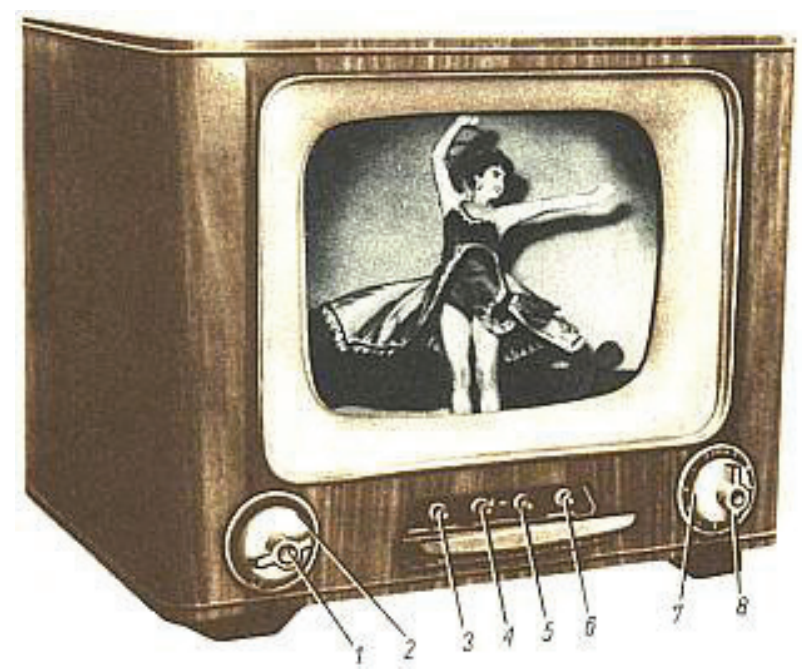

Figure 5. Tube TV-set of the late 1950s. Source: W. Trusz and J. Dombrowicki, Radio i telewizja w domu (Warsaw: Wydawnictwo Komunikacyjne, 1958). 
were covered, with reviews, previews and critical and celebrity pieces..$^{8}$ However, unlike these other cultural and media forms, the output of radio was immense. It broadcast daily from many stations serving local, regional, national and international audiences. This type and amount of information could not be covered in the same way as that provided for cinemas and theatres. Therefore, the newspapers created a form of listings more suited to this mass audio output. With the listings, the newspapers represented radio's complex ephemeral form of output diachronically and synchronically, providing a view of radio as being organised and ordered around a station's daily chronological output but with numerous stations on offer, this also meant that radio was presented as having many programmes on offer at any one moment. Such a form of representation suggests, on one level, that a defining feature of radio was choice occurring over time and, on another level, that choice existed at any single moment in time. From the analysis above, the balance between these two tensions would change, depending on the papers, radio's output and the wider context. For example, in the I920s, British newspapers had a bias towards the diachronic because of their focus on the limited range of BBCo stations; this shifted towards more of a balance between the diachronic and synchronic in the I930s, as papers expanded their coverage to include the new national programme and European stations; this was followed, with the outbreak of war, with a more diachronic form of coverage, as the number of BBC stations were reduced and European stations lost their appeal; while, in the I950s, the listings coverage moved back to more of a balance, as more national stations began to appear. The listings also provided a spatial-locational view of radio, through information on where the stations could be found on the airwaves, such as with call signs and frequency information, but also a geographic view, of where the station was broadcasting. As shown, due to changes in radio broadcasting, the needs of the press and the wider social, cultural and political developments, this form of coverage moved from a regional-local view of radio in the early ig20s, to a national, regional and European view in the I930s, and then to a more national view in the I940s and I950s.

While radio waves cannot be touched or seen, only listened to via a medium, the radio set, the listings provided a means of visually representing this ephemeral form on the printed page. The listings have, over time, been shaped and formed through an interaction between the needs of both radio and the press operating within the wider societal context. It was a form of coverage, along with the highlights, which provided the reader with a way of knowing what was on, what might be worth listening to and when. The coverage, the form the listings and highlights took, differed between different types of papers, as the newspaper and those working there acted as culturally intermediaries shaping the coverage to fit the presumed tastes of their readers. By studying the listing and highlights over time, we get an important historical insight in to how the intermediality between radio and newspapers developed and changed, and how it has played an important role in how radio was, and indeed still is, represented to the reader and listener.

\section{Notes}

I. Kate Lacey, “Ten Years of Radio Studies: The Very Idea,” The Radio Journal: International Studies in Broadcast and Audio Media 6, no. I (2009): 2I-32. 
2. Siân Nicholas, "Media History or Media Histories? Re-Addressing the History of the Mass Media in Inter-war Britain," Media History I8, no. 3-4 (2012): 379-394, specifically 309.

3. Paul Rixon, "Radio and Popular Journalism in Britain: Early Radio Critics and Radio Criticism," The Radio Journal: International Studies in Broadcast and Audio Media I3, no. I-2 (2015): 23-36.

4. Nicholas, "Media History or Media Histories?", 38r.

5. Todd Alvery, Radio Modernism: Literature, Ethics, and the BBC, 1922-1938 (Aldershot, Hampshire: Ashgate, 2006); Jeroen Dera, "The Broadcaster's Catacombs: Looking for Literature in a Dutch Listings Magazine," Journal of European Periodical Studies 2, no. 2 (Winter, 20I7): 77-93; Gwenyth L. Jackaway, Media at War: Radio's Challenge to the Newspapers, 1924-1939 (Westport: Praeger, I995); David Hendy, "The Dreadful World of Edwardian Wireless," in Moral Panics, Social Fears and the Media: Historical Perspectives, ed. Siân Nicholas and Tom O’Malley (Abingdon; Routledge), 76-89; Nicholas, “Media History or Media Histories?”; Paul Rixon, Radio Critics and Popular Culture: A History of British Radio Criticism (London: Palgrave, MacMillan, 20I8).

6. Dera, “The Broadcaster's Catacombs," 77.

7. Suzanne Lommers, Europe - On Air: Interwar Projects for Radio Broadcasting (Technology and European History Series) (Amsterdam, Holland: Amsterdam University Press, 20I2), 40; Paul Rixon, "The Role of British Newspapers in Framing the Public Perception and Experience of European Radio I930 to I939," Media History (2018) DOI: 10.1080/13688804.2018.153964I.

8. For more on the Radio Times see: Tim Currie, The 'Radio Times' Story (Tiverton: Kelly Publications).

9. Rixon, Radio Critics and Popular Culture, I33-162.

Io. Juha Herkman, "Introduction: Intermediality as a Theory and Methodology," in Intermediality and Media Change, ed. Juha Herkman, Taisto Hujanen and Paavo Oinonen (Tampere: Tampere University Press, 20I2), IO-28.

II. Jennifer Smith Maguire and Julian Matthews, "Are We All Cultural Intermediaries Now? An Introduction to Cultural Intermediaries in Context," European Journal of Cultural Studies I5, no. 5 (2012): 55I-562.

I2. For more on flow see: Raymond Williams, Television: Technology and Cultural Form (Glasgow: Fontana/Collins, I979), 9I-92; John Ellis, Visible Fictions: Cinema; Television; Video (London: Routledge, I982), III-I26, I27-I44, I45-I59; John Corner, Critical Ideas in Television Studies (London: BFI, I999), 65.

I3. In terms of TV and the diachronic see: Ellen Seiter, "Semiotics, Structuralism, and Television," in Channels of Discourse, Reassembled: Television and Contemporary Criticism, ed. Robert C Allen (Chapel Hill: University of North Carolina Press, I992), 3I-66, specifically 48-49.

I4. Seiter, "Semiotics, Structuralism".

I5. Kate Lacey, "Listening in the Digital Age," in Radio's New Wave: Global Sound in the Digital Era, ed. Jason Loviglio and Michele Hilmes (Routledge: London, 2013), 9-23, specifically I4-I5.

I6. Also see work by Andreas Fickers on the materiality of the radio dial: Andreas Fickers, "Visibly Audible: The Radio Dial as Mediating Interface," in The Oxford Handbook of Sound Studies, ed. Trevor Pinch and Karin Bijsterveld (Oxford: Oxford University, 20I3), 4II-439.

I7. Maguire and Matthews, "Are We All Cultural Intermediaries Now?" I6-I7.

18. Rixon, Radio Critics and Popular Culture, II-32.

I9. Jennifer Smith Maguire, "Bourdieu on Cultural Intermediaries," in The Cultural Intermediaries: Reader, ed. Jennifer Smith Maguire and Julian Matthews (London: Sage, 20I4), I5-24, specifically I6-I7.

20. Colin Seymour-Ure, The British Press and Broadcasting since 1945 (Oxford: Blackwell, I993), 27-33.

2I. Tom Crosbie and Jonathan Roberge, "Critics as Cultural Intermediaries," in Knowledge for Whom? Public Sociology in the Making, ed. Christian Fleck (London: Routledge, 20I6), 275-297, specifically 276.

22. Seymour-Ure, The British Press and Broadcasting since 1945, I8-21, 27-33.

23. For each paper ten pages were collected between I922-24; ten pages for each paper for the period I932-38; ten pages per paper for I940-42; and ten pages per paper for I954-58.

24. For more on how the media industry imagines its audience see: Ien Ang, Desperately Seeking the Audience (London: Routledge, I99I).

25. David Howarth, Discourse (Buckingham: Open University Press, 2000), I3I

26. Asa Briggs, The History of Broadcasting in the United Kingdom: The Birth of Broadcasting, Vol. I (London: Oxford University Press, I961), 32, 37.

27. Rixon, "Radio and Popular Journalism in Britain," 26-27.

28. Ibid., 27-28.

29. Lacey, "Listening in the Digital Age," I4.

30. Sean Street, The A to $Z$ of British Radio (Lanham: The Scarecrow Press, 2009), 49-50, 164. 
3I. Rixon, Radio Critics and Popular Culture, 42.

32. “Week-End Wireless," Manchester Guardian (3 March I923): I3.

33. Currie, The 'Radio Times' Story, 20.

34. Ibid.; Briggs, History of Broadcasting, 203.

35. Broadcast on Manchester 2ZY: "Broadcasting," Daily Mail, 9 December, I922, IO.

36. “'2Lo' Calling," Daily Mirror, 23 February, 1923, 2.

37. Currie, The "Radio Times" Story, 3.

38. Ibid., 7-I4.

39. Briggs, History of Broadcasting, I42; Currie, The "Radio Times" Story, 4.

40. Ibid.; Nicholas, "Media History or Media Histories," 386.

4I. Brian Franklin, Newszak and News Media (London: Arnold, I997), II7.

42. Dan LeMahieu, A Culture for Democracy: Mass Communication and the Cultivated Mind in Britain (Oxford: Clarendon, I988), 275 .

43. Nicholas, "Media History or Media Histories," 286.

44. Paddy Scannell and David Cardiff, A Social History of British Broadcasting. Volume One 1922-1939 (London: Basil Blackwell, I99I), 230.

45. Nicholas, "Media History or Media Histories," 286.

46. "Entertainment pages," Daily Mail, I January, I935, I7.

47. "Weekend Programmes," Daily Express, II November, I933, I3.

48. "Weekend Programmes," Daily Express, II November, I933, I3.

49. Martin Conboy, Journalism: A Critical History (London: Sage, 2008), I78.

50. "Radio," Daily Express, 20 June, I938, I9.

51. “To-Night's Features,” Daily Mail, 22 March, I935, 21.

52. Paul Rixon, Radio Critics and Popular Culture, 72-73.

53. “'The Boomerang Bet' - A Radio Thriller,” Daily Telegraph, I8 November, I935, 8.

54. "Week-End Wireless Notes and Programmes," Manchester Guardian, 8 May, I937, 2.

55. "Broadcasting," The Times, 24 January, I935, Io.

56. , "Week-End Wireless Notes and Programmes," Manchester Guardian, 8 May, I937, 2.

57. "Broadcasting," The Times, 24 January, I935, Io.

58. Rixon, "The Role of British Newspapers," Io.

59. Rixon, Radio Critics and Popular Culture, Io6-II5.

6o. Kevin Williams, Read All About It! A History of the British Newspaper (London: Routledge, 20I0), I76.

6I. Currie, The "Radio Times" Story, 44; Street, A to Z of British Radio, I38.

62. Ibid., пі6.

63. “To-Day's' Radio," Daily Mirror, in March, I940, I6.

64. “Radio," Daily Mail, 3I December, I942, 2.

65. "Broadcasting," The Times, I9 December, I942, 2.

66. Home Service: "Broadcasting," The Times, I9 December, I942, 2.

67. Rixon, Radio Critics and Popular Culture, II7.

68. Street, $A$ to $Z$ of British Radio, 234.

69. “Television and Radio," Daily Mirror, I January, I954, 8.

70. Philip Purser, Done Viewing: A Personal Account of the Best Years of Our Television (London: Quarter Books, I992), 3I.

7I. Andrew Crisell, An Introductory History of British Broadcasting (London: Routledge, I997), I35.

72. “Broadcasting Programmes," Daily Telegraph, I January I957, 4.

73. Richard Witt, “Needle Time: The BBC, the Musician's Union, Popular Music, and the Reform of Radio in the I96os," Popular Music History, 7, no. 3 (2010): 24I-262.

74. Daily Mail, 3 December, I956, 9.

75. Peter Black, “Teleview," Daily Mail, 3І January, І956, І2.

76. Manchester Guardian, I May, I958, I5.

77. Street, $A$ to $Z$ of British Radio, 164-165.

78. Rixon, Radio Critics and Popular Culture. 


\section{Biography}

Paul Rixon is a reader in radio and television at the University of Roehampton. He has published extensively on American programmes, British television, television and radio critics and the media coverage of war in various journals. He is the author of three monographs, American Television on British Screens, TV Critics and Popular Culture and Radio Critics and Popular Culture. His latest area of research relates to the domestic consumption of radio through smart speakers such as the Amazon Echo and Google Home. 